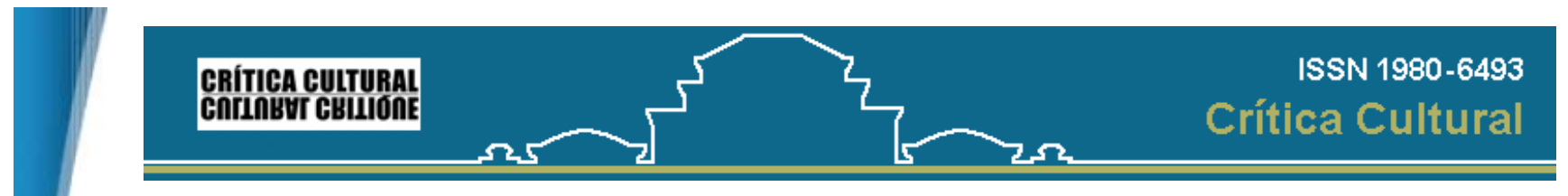

Crítica Cultural, volume 1, número 2, jul./dez. 2006

\title{
FICCIÓN Y POLÍTICA EN RESPIRACIÓN ARTIFICIAL: UN INVENTARIO DE LÍMITES
}

\author{
Maria Cândida Ferreira de Almeida-
}

Resumen: Este trabajo trata de presentar una serie de posicionamientos de Ricardo Piglia, marcados por una preocupación con la "verdad", acerca de su producción narrativa y sobre política, las dos entremezcladas con mis propias concepciones de crítica literaria y de política. Eleg entre las series presentes en del escritor argentino la que me pareciera más importante para comprender también, de algún modo, la cultura de su país: la oposición ficción y realidad, infiltrada por una cierta noción de política leída bajo la metáfora del tango. Al final, confronto las palabras de Piglia con las de Carlos Gardel.

Palabras-clave: crítica; política; literatura latinoamericana; Ricardo Piglia.

\author{
1 Introducción \\ hacer de la política una prioridad absoluta en la vida \\ es el camino cierto para la locura \\ Roberto Bobbio
}

Este trabajo presentará una serie de posicionamientos de Ricardo Piglia acerca de la producción ficcional y de la política entremezclados y abordado sobre mis propias concepciones de crítica literaria y de política, para, luego, comparar el propio tango como metáfora política de la cultura argentina. Elegí entre las series presentes en la obra crítica y literaria de Piglia la que me pareciera más importante: la oposición ficción y realidad, infiltrada por una cierta noción de política, este confronto de perspectivas implican un embate dual sin contornos de anulación pero si, de suplemento, de adición, pues cada una de las partes necesita de la otra para seguir, como la pareja de bailadores. La ficción tiene en la realidad su fundamento, así como la realidad tiene en el lenguaje su posibilidad de configuración. Piglia y el tango ponen en los escenarios estos trazos, líneas y fricciones.

Empiezo por dibujar un mapa de mis propias perspectivas sobre literatura para, luego, demostrar en que términos mis posicionamientos están próximos o alejados de los de Piglia. Me formé en crítica literaria estudiando en el área de concentración de la "literatura comparada", en una época de sus movimientos más expansivos, cuando no se empuña más límites a lenguaje a ser manoseada por el estudioso del arte escrita. Dentro de esta perspectiva, todos los textos son leídos como texturas pasibles de colaborar con la labor crítica: música popular, cinema, filosofía, artes pictóricas, psicoanálisis, antropología, discursos políticos, todo nos parece estar a la disposición del crítico literario, como siempre había estado a la disposición del escritor al erigir su obra.

Las opiniones "verdes" de mis años iniciales como filóloga colaboraran mucho para que yo estuviera abierta a los problemas planteados por los "pastiches" literarios que suscitan pasión en los lectores más ingenuos, no viciados en las categorías tradicionales que suelen limitar la concepción y lo desfrute de la literatura.

Sin apoyarme en paradigmas arraigados, estuvo, por esto mismo, más predispuesta a las "revoluciones" teóricas que desmontaban la disciplina "teoría literaria". A través de la teoría comparatista pudo ponderar las dudas que surgían en mis investigaciones de neófita, una vez que en los diversos momentos de esta época inicial encuéntreme sin soportes. Pronto, en la pos-graduación, tuvo la oportunidad de trabajar con textos fundamentales del pensamiento sobre literatura como "Tradición y Talento individual", de T.S.Eliot, "Tradición y Ruptura", de Octavio Paz, "El orden del Discurso", de Michel Foucault, "O Entre-lugar do discurso latinoamericano" de Silviano Santiago o "Ficciones de Fundación" de Doris Sommer, "Kafka: por una literatura menor" de Gilles Deleuze y Félix Guatarri. Como en un movimiento continuo en instancias diferenciadas discutí la cuestión de la construcción de los cánones; el valor de las contra-literaturas, tales como la literatura oral, los "comics", las películas; de la herencia y la contra-herencia; esos embates teóricos se completaban y redundaran en cambios de mis puntos de vista que fueran en estudios posteriores mejor desarrollados, y que ahora me son útiles para la lectura de la obra de Ricardo Piglia. En la producción estética pigliana la cultura de entretenimiento, tipo "comics", cine y las narrativas marginales de nuestra época están en diálogo con la cultura canónica, como es propio de la hechura de una parte prestigiada de la literatura contemporánea. La obra de Piglia es una obra abierta a todos estos tópicos, como ya veremos. Leer a Piglia corresponde al deseo de profundizar mis reflexiones sobre la narrativa y su constitución, como estos tópicos, como ya veremos. Leer a Piglia corresponde al deseo de profundizar
antes, lo estudio de las contra-literaturas me propiciaran una penetración en el tema.

La comprensión de los estudios literarios como literatura comparada en su vertiente pos-moderna no se hacen efectivos sin conocer la producción argentina, especialmente, los "tíos" de Piglia, entre ellos, en especial, Jorge Luís Borges, que en dos textos fundamentales "Kafka y sus precursores", "Funes: el memorioso" y "Pierre Menard, autor del Quijote"- forneció las directrices más alabadas sobre el tema. El primero es cardinal por debatir la sucesión cronológica en el montaje de la tradición. Borges pone en jaque la sucesiones, hasta mismo las continuaciones del tipo "de tío a sobrino" electa por Piglia, como el aclara en Respiración Artificial - "Alguien, un crítico ruso, el crítico ruso luri Tiniánov, afirma que la literatura evoluciona de tío a sobrino (y no de padres a hijos)" (PIGILIA, (1988) 1993, p.19) - pues esta sigue siendo cronológica, y sigue atendiendo uno de los presupuestos más caros a Hegel - transformación como evolución - para comprender el "espíritu de la historia".

Ya "Funes" ridiculiza la memoria sin olvido, sin ruinas, sin perdidas, propia de la tradición de la "historia archivista" criticada por Niestzsche (NIETZSCHE, 1988), que todo quiere guardar por ser del pasado, sin ningún criterio. Borges crea el asombro de una preservación que destruye el presente, donde no contiene más nada que los materiales pasados.

En la actualidad, los aparatos críticos de la literatura se abren en dos vertientes intercambiables: literatura comparada y estudios culturales, con los viejos paradigmas destrozados, buscamos la creación de nuevos o la restauración de aquellos que todavía sirven para la labor crítica. En cuanto la literatura comparada aun busca su metodología, Stuart Hall y los demás del grupo de Birminhan dan el tono de los "estudios culturales", cuya tópica está centrada en: 1) la intervención social; 2) en el contexto institucional y social; 3) en la inter 0 transdiciplinaridad; 4) en temas de la cultura de masa y, 5) en la capitalización por la academia de los discursos sociales presentes en la crisis de los viejos paradigmas que regían a la ciencia y al arte.

En el conjunto de su obra Piglia atraviesa de construcción "puramente" literaria a los cuestionamientos de los estudios culturales, pues cuenta su versión de la "historia literaria" de Argentina, por medio de Respiración Artificialy en Argentina en Pedazos, un libro de comics que trae bajo la forma poco ortodoxa y más accesible de dibujos una elección cuentos canónicos que dan visibilidad para la contradicción social de Argentina. A pesar de criticar la cultura de masas como anti-política e incapaz de "establecer con claridad la distinción entre verdad y de Argentina. A pesar de criticar la cultura de masas como anti-politica e incapaz de "establecer con claridad la distinción entre verdad y
ficción" (PIGLIA, 1986, p. 211), Piglia no duda en recurrir a un de sus productos, que, con certeza alcanza un público mucho más amplio que el de la literatura convencional en forma de novela.

Pero es en la crítica que Piglia centra la fuerza de su proyecto de escritura, pues para él "la crítica trabaja con la verdad de otro modo. Trabaja con ciertos criterios de verdad más firmes y a la vez más nítidamente ideológicos". Es papel del crítico literario producir una verdad en oposición a la ficción que pone en crisis cualquier verdad: "Toda el trabajo de la crítica, se podría decir, consiste en borrar la incertidumbre que define a la ficción. El crítico trata de hacer oír su voz como una voz verdadera” (PIGLIA, 1986, p. 13).

Lo rastreo de fuentes, la caracterización de personajes, el diálogo literatura e historia, ya son caminos conocidos, muchas veces palmeados. Creo que se fuera solamente este objetivo al sondear los andamios teóricos de Piglia, ya habría logrado, hasta mucho más de lo que puedo mesurar. Estudiar la historia de la literatura argentina por medio de la perspectiva del argentino fue más, la obra de Piglia me abrió para el cosmos cultural de aquel país que para mí hace parte fundamental de este inmensurable que es América Latina; tal ejercicio significó acceder a otro lenguaje, hablando de manera más específica, hoy creo que puedo leer algo del código literario argentino con ojos argentaos. Es un aprendizaje en conflicto, como suelen ser los procesos imprescindibles (uso otra vez una hipérbole) para comprender una distinta parte de la hispanidad dada a ausencia de repetición entre la historia argentina y la brasileña. 


\section{El narrador sospechoso}

Piglia explica su proyecto de escribir Respiración Artificial como sendo la idea de "hacer un archivo", "me tentaba la idea de un archivo como forma" explica el autor; mi aproximación a la novela se dio justamente por el reconocimiento de parte de su "archivo" como similar al que yo tuve acceso en mi formación intelectual. Autores como Hegel, Hermingway, Musil, Kant, Kafka, Jackobson, Tinianov, Thomas Moro, Francis Bacon, Diderot, Balzac, Sade, Laclos, Montesquieu, Weber, Wittgenstein, Voltaire, Descartes, Borges, Cortazar, Dickens, Michelet, Sthendal me son conocidos, hacen parte de mi información; pero no me sonaba de nada los Generales Uriburu, Mitre, Roca; los escritores Lugones, Echevarría, Alberdi, De Angelis, Macedonio Fernández. Por lo tanto, afrontarme a narrativa de Piglia fue como navegar por aguas conocidas llenas de peligrosas piedras que me detendrían a reflexionar, que ampliarán los límites de mi mundo.

Como resultado de esta escritura-archivo, Respiración Artificial es una novela descentrada, no posee un hilo único que conduzca la narrativa; pero podríamos decir que trata fundamentalmente de los despojos intelectuales de Enrique Ossorio, cuyo apellido nos remete a "ossos", como se escribe "huesos" en portugués y a osario, que en castellano se define por ser "en las iglesias o en los cementerios, lugar destinado para reunir los huesos que se sacan de las sepulturas a fin de volver a enterrar en ella"(Diccionario de la Real Academia Española).

Así, yo resumiría la novela, como un rescate de los huesos de la cultura argentina a través de sus historias literaria y política rescrita en una novela contra-histórica. El modelo de la contra-historia nos da el propio Piglia al querer que Ossorio fuera a la vez la hilo de su narrativa y "un personaje que fuera la inversa de Sarmiento", "[o] sea, que perdió, no el que llegó primero"; por sus demás características Enrique Ossorio sigue toda la trayectoria y perfil de Sarmiento: fue su compañero, hace el exilio y es un intelectual burgués, que opta por la política. En

resumen: “Este personaje es el que en Respiración...arrastraría la problemática de la historia argentina” (PIGLIA, 1986, p.112).

En la lectura de Respiración Artificialy de otras narrativas de Piglia - Prisión Perpetua, Nombre Falso, Formas Breves, Argentina en Pedazos - constatamos que, terminantemente, ningún narrador de cualquier texto pigliano se mantiene en la plenitud de una presencia. Su escritura depende siempre del vínculo que mantenga con otros elementos, sean ellos advenidos de la realidad, de otras obras del autor y de otros autores, hasta del mismo texto que narra. Pero, desde luego, Piglia nunca deja de tener en cuenta que si un elemento del texto existe all es por que repite radicalmente algunos de los elementos que componen los demás textos. No hace sentido, por consiguiente, desplazar a la escritura el carácter conclusivo que el paradigma "realidad" concede, en algunos puntos de vista, a la palabra escrita.

En esto modelo narrativo, que, además, opera con el "archivo", ningún bloque de la escritura puede aspirar al privilegio sobre los demás, porque depende tanto de aquellos elementos de los cuales difiere como de aquellos elementos a los cuales sucede. Por esto, en la lectura de Respiración Artificial nos abstenemos cuidadosamente de atribuir a un narrador - Emilio Renzi, Marcelo Maggi, Enrique Ossorio Luciano Ossorio, Tardewiski, Marconi - la hegemonía que el Benjamin localizaba en su modelo de narrador moderno. Todos participan de la narración de la novela aportando dados imprescindibles para el montaje final del texto.

En su labor crítica, Piglia redelinea este tipo de narrador de Walter Benjamín (1967), tomando como paradigma a Mansilla, cuyo jefe ranquel ejerce su poder a través del uso da la palabra: "Un poder incierto, basado en el convencimiento, en la verdad del otro, en la creencia. En el poder de la palabra. En esas sociedades el Estado es el lenguaje. El talento verbal es una condición y un instrumento del poder político. El jefe es el narrador de la tribu" (PIGLIA, 1986, p.120).

Este narrador confiable descrito con cierta nostalgia por Piglia, de hechura benjaminiana, que narra sus experiencias, presentándolas como "verdad" o como estrategia para alcanzar la verdad al receptor que lo escucha - cuya "eficacia" estaría ligada "a la verdad, con todas sus marcas: responsabilidad, necesidad, seriedad, la moral de los hechos, el peso del real"( PIGLIA, 1986, p.121) - desaparece en la "civilización" como "antagónica" al "uso político del lenguaje", para Piglia "La ficción se asocia con el ocio, la gratuidad, el derroche de sentido, lo que no puede enseñar; se asocia con el exceso, con el azar, con las mentiras de la imaginación, como diría Sarmiento. La ficción aparece como una práctica femenina, una práctica, digamos mejor, antipolítica" (PIGLIA, 1986, 121). Para Piglia hay una oposición entre "El espacio femenino y el espacio político" - todo esto está por supuesto en Respiración Artificial, cuyos narradores, todos ellos hombres, blancos y burgueses rescriben o escriben una contra-historia de Argentina. En lugar del narrador político del siglo XIX, encontramos en Respiración Artificial el narrador "sospechoso" de la Pos-modernidad, que pierde la Verdad a favor de la "verdad construida" (PIGLIA, 1986, p. 211).

La voluntad manifiesta de Piglia es deshacer la dicotomía entre escritura y vida y, como también desmantelar toda narrativa que aspire a un carácter absoluto, que sólo ser mantendría si se desdeñara un hecho fundamental: la posibilidad de la vida misma sin el logos, la posibilidad de realidad fuera del logos. "La ficción trabaja con la verdad para construir un discurso que no es ni verdadero ni falso. Que no pretende ser ni verdadero ni falso. Y en ese matiz indecidible entre la verdad y la falsedad se juega todo el efecto de la ficción" (PIGLIA, 1986, 13).

No es posible ignorar en tal caso, efectivamente, que los términos de esta oposición vida / escritura o realidad / ficción se sustentan entre sí. Si bien nunca llegan a coincidir del todo, no sólo se encuentran referidos el uno al otro sino como, de hecho, se necesitan recíprocamente. Incluso se podría afirmar que cada uno de ellos, en cierto modo, consiste parcialmente en el otro; la función dominante de un término sufre una violenta acción reactiva del término que se pretende dilatar. En el texto de Piglia, según Carmen de Mora, "existe una verdad que no es dada, directa, surge de la lucha, de la confrontación del poder" (DE MORA, 2005)

Un ejemplo de la subordinación - realidad/ficción - producida de manera asimétrica lo aporta la tradición borgeana, comprometida con dicotomías tan prestigiosas como las de realidad/apariencia y sensible/inteligible, pero en la cual la palabra suplanta la realidad. El deleite borgeano con las polaridades, precisamente, indica la voluntad de conformar la realidad únicamente por medios expresivos, pues fuera del lenguaje impera el caos. Por eso rechaza las oposiciones binarias tradicionales, tales como cuerpo / espíritu o espacio / tiempo, que viene a ser lo mismo que la oposición - finito / infinito -, colocando la escritura en el centro de su preocupación, que podríamos decir, filosófico-literaria, propone obrar sobre el finito de la palabra frente al infinito de sus significados: "no hay en la tierra una sola página, una sola palabra que lo sea [sencillo], ya que todas postulan el universo, cuyo más notorio atributo es la complejidad" (BORGES, 2003, p. 8).

De hecho Borges defiende una peculiar noción de realidad, la cual hereda Piglia, que nos invita a concebirla como un entramado de relaciones donde la ausencia, evocada únicamente por el lenguaje, es como mínimo tan importante como la presencia de las cosas, personas, hechos históricos, etc. Es decir, que así como el lenguaje, la realidad también aparece despojada de cualquier "centro". Respiración Artificial refleja esta concepción de verdad pues en la narrativa la realidad es imposible de ser expresada directamente a causa de los límites del lenguaje, "hay que escribir desplazado, hacia otra enunciación" (DE MORA, 2005).

En Piglia, este descentramiento inmuniza contra las dicotomías, siempre indeseables aunque pretendan esclarecer u organizar la narrativa. Al fin y al cabo, las referencias a un eventual centro totalizador, como le parece que demuestra la tradición literaria "realista", para darle algún nombre, han sido siempre fáciles:

Me interesa trabajar esa zona indeterminada donde se cruzan la ficción y la verdad. Antes que nada porque no hay un campo propio de la ficción. De hecho todo se puede ficcionalizar. La ficción trabaja con la creencia y en ese sentido conduce a la ideología, a los modelos convencionales de realidad y por supuesto también a las convenciones que hacen verdadero (o ficticio) a un texto. La realidad está tejida de ficciones. La Argentina de estos años es un buen lugar para ver hasta qué punto el discurso del poder adquiere a menudo la forma de una ficción criminal. El discurso militar ha tenido la pretensión de ficcionalizar lo real para borrar la opresión. (PIGLIA, 1986, P. 10-11)

En Piglia, consiguiente, lo que hace posible el lenguaje reside en la ausencia, pero ésta no moviliza el lenguaje como lo haría una determinación exterior a un ser sometido, a un ser oprimido. Sus efectos, por ejemplo, no son comparables a los de la verdad en el modelo dependiente de la mimesis, y menos aún la fuerza externa equivale a un origen. En todo caso, su novela Respiración Artificia/crea un paradójico de la búsqueda de un origen que es a la vez anti-originalidad, puesto que jamás podría ser ni aprensible en una sola tradición, ni una en sí misma. La narrativa pigliana de la "no-origen", es, con todo, extrañamente articulada. Sobre todo habrá que leerlo como "pos-moderno" y, a mismo tiempo, "moderno" en las construcciones genealógicas que afirman su derecho a la herencia múltipla que revindica - movilizando las diferentes tradiciones literarias, no solo argentinas, pero occidentales, que son precisamente fabricantes de su lenguaje. Emilio Renzi busca a su tío, Marcelo Maggi Pophan, quien busca a Enrique Ossorio a través de Luciano y de Esperancita, pequeña esperanza que también es ilusión expectación, anhelo, perspectiva, así, busca sustantivada de los "fragmentos de la historia" pública "construida" en los meandros de la vida expectacion, anhelo, perspectiva,
privada (PIGLIA, 1993, P. 26-27).

Piglia mantiene en la narrativa que produce los efectos de diferencia y repetición que en definitivo equivale al propio lenguaje. También procura mostrar a lo largo de sus narrativas y producción crítica que todas las instancias del discurso se integran en este juego de apariencias e ilusiones. Teniendo en su poder este instrumental Piglia aborda sus temas cruciales: la historia literaria y política de Argentina.

\section{3 “La cicatriz de la zanja”}

¿Cuál la relación que la literatura tiene con la política? Tomando el concepto de política como aquello que expresa la objetividad de las relaciones humanas, preguntamos también: ¿cuál la relación que la literatura tiene con la política? Esas son preguntas que atraviesan históricamente el cotidiano de los profesionales, como yo, de la palabra, escrita y hablada. Mismo antes de la rotura establecida con el deber de docere, educar, que la religión impuso a la literatura, cisión esta que dio lugar al delectare, deleitar, al placer del texto, del "arte por el arte", desde entonces, aristotélicamente, ya nos preguntábamos: ¿Para que rayos sirve la literatura?

Si la literatura es solamente para la fruición estética e individual, ¿en qué ella sirve para la sociedad? Si entendemos la literatura 

estos dos artes?

La inutilidad discursiva de los estudios literarios tiene angustiado muchos de nosotros, latinoamericanos, estudiantes y profesionales de las Letras, cuando jóvenes o no tan jóvenes. La mala conciencia manifestase delante de países repletos de problemas urgentes, en cuanto nosotros, frecuentemente con dinero público, somos pagos para leer, escribir y hablar acerca de literatura. Un arte, en lo más de las veces, reaccionaria, pues es producida por la clase letrada que, llena de privilegios, encuentra en las páginas en blanco más un espacio para defenderlos; justificando, en letras, la vergonzosa diferencia económica que asola nuestra América.

El texto de Piglia opta por colocar este dilema en la literatura como "una claridad" frente "la opacidad" del discurso social; la claridad aparece alli como una "virtud" para enfrentar la "oscuridad" deliberadamente manipuladora de algunos discursos políticos. La narrativa adquiere así una estructura paródica, des-constructora del discurso impermeable de la política autoritaria. En aquellos momentos en Argentina el Estado actuaba según la premisa de la "prerrogativa", concepto nombrado por Locke que significa la facultad del Estado de actuar "sin contar con la prescripción de la ley y, a veces, incluso contra ella", aunque siempre "con vistas al bien público" (MARATÓ Y RIU, 1996). El proyecto de "bien público" de la dictadura argentina difería en gran medida con la de sus opositores pero el uso de la violencia extremada calló a ellos.

Con todo, Piglia busca a la "concordia", su narrativa desemboca ahí, en un pueblo fronterizo, con "tipos" de la intelectualidad argentina: el intelectual criollo, el intelectual inmigrante, el intelectual exilado en su propia tierra, y el intelectual en formación para presentar su perspectiva de la situación argentina de aquel momento: la dictadura militar de los años 70 del siglo XX.

La parodia tornase el programa apropiado por Piglia para de-construir el autoritarismo y el conflicto de una sociedad dividida; en su narrativa percibimos que defiende, por un lado, que la realidad irrumpe necesariamente en la palabra y en la ausencia y, por otro lado, que el lenguaje torna presente tanto el sentido como la verdad ocultada. Es decir, la palabra re-presenta directamente el significado que habita en la mente del narrador, así, fortalece el enaltecimiento tradicional de la palabra en detrimento de la realidad.

Piglia utiliza la de-construcción paródica como un gesto que trata de desmontar el edificio del silencio impuesto por la dictadura, para que, a través de su escritura, aparezcan las estructuras del poder autoritario: el censor, la prisión de Marcelo, su desaparición, exilio, Luciano Ossorio cerrado en su habitación, etc. Pero una vez puestas en cena se muestran como fragmentos de la Historia Oficial: "He tratado de

construir mis relatos a partir de lo no dicho, de cierto silencio que debe estar en el texto y sostener la tensión de la intriga" (PIGLIA, 1986, p. 100). Aquella cualidad re-presentativa es precisamente la que le ha sido denegada a la escritura de Piglia. A lo largo de la novela sólo se puede percibir la expresión subalterna de intelectuales que suele representar únicamente su propia palabra, adaptados, como están a la "lógica del posible": "Pensar en el lugar de los políticos. Ésa es la tendencia hegemónica. Los intelectuales hablan como si fueran ministros. Se habla de la realidad con el cuidado y el cálculo y el tipo de compromiso y el estilo involuntariamente paródico que usan los que ejercen directamente el poder" (PIGLIA , 1986, p.102).

Los personajes de Piglia también representan, como en el siglo XIX, la figura del individuo aislado, que se puede proyectar como el escritor en su gabinete o inmerso en la ciudad. Exilado o alienado, colocado contra el telón-de-fondo de la multitud o de la metrópoli anónima e impersonal; en el caso de Respiración Artificial, están recogidos en el pueblo como el pasante o como un jugador temporal del ajedrez. Así lo figuró Charles Baudelaire, en "el pintor de la vida moderna", personaje que "eleva su casa en el corazón de la multitud", en medio del ir y venir de los movimientos urbanos. "en medio del esquivo y al infinito" que "se torna un único cuerpo con la multitud, entra en la multitud como se fuera un embalse de energía eléctrica". Imagen para cual Ricardo Piglia hace eco en "Retrato del Artista" (PIGLIA, 2000), donde escribe el compositor, dentro de su casa que abre la ventana y compone en sintonía con el ruido de la calle, Piglia agrega el factor pos-moderno al inventar una recusa de exhibición pública de la obra.

Así son los intelectuales pueblerinos de Piglia, seres que viven inmersos en sus propias palabras incapaces de comunicarse con su entorno a través de ellas. No sabemos de Tardewiski o de Marconi nada más que los discursos - dijo que dijo que dice que dije - presentando versiones atacañadas de un cierto criollismo o de un incierto cosmopolitismo. La concordia buscada es de discursos, pero hace falta más, mucho más para que Argentina reanude su trayectoria.

4 La concordia en los pasos del Tango

No, el tango no representa la repetición de la traición como dijo Piglia. No, no se trata del "hombre abandonado" que habla "a la mujer perdida y se queja de su traición". El tango no es un lamento del "hombre engañado, escéptico, amargado, moralista sin fe", que "apostrofa al mundo" (PIGLIA, 1993). No, no es esto. El tango es el cantar, el sonido de la tentativa de concordia entre los opuestos, sean cuales sean, son hombres y mujeres que elegirán caminos distintos y que han de volver para prestar cuentas, es el arreglo de la ida en la vuelta; es el acuerdo entre los desacuerdos entre los unitarios y los federales que fundó Argentina. Tango es la posibilidad de la concordia de opuestos - en la metáfora de los opuestos conciliables, hombre enlazado a mujer, quieren seguir juntos por más difíciles que sean los caminos de la vida, por demasiado grave lo que hay que perdonar, por más opuestos que se dibujen los pasos, ellos volverán a estar uno delante del otro y seguirán juntos. Argentina suele representarse en opuestos - racistas y antirracistas, peronistas y antiperonistas, unitarios y federales por lo tanto, para seguir sus pasos Argentina debe siempre experimentar la conciliación, debe irse a Concordia, uno de los caminitos que los lleva allá es el Tango.

Tango es polaridades de opuestos que quieren el equilibrio. Tango es el híbrido. "Tango es un ser mitológico, mitad hombre, mitad mujer; un monstruo que se abraza a sí mismo."(Abadia) Es, tal como la literatura, una "contra-historia" de lo que no se puede hablar solo con el lenguaje de los signos, habla el cuerpo, habla el suspiro, habla la soledad compartida.

Tango es la imposibilidad de matar el otro, tan lejos, tan próximo. Gardel habla por veces de la dificultad de matar la amada quimérica, como en el clásico Amargura, cuando las manos no alcanzan ejecutar el acto extremado - Un viento de locura/ atravesó mi mente/ deshecho de amargura/ yo me quise vengar/ mis manos se crispaban /mi pecho las contuvo / su boca que reía / yo no pude matar-; matar es venganza sencilla y violenta.

La Argentina herida por los horrores pide justicia y no venganza, contesta la senadora peronista Cristina Fernández de Kirchner cuando preguntada que había lesionado el país y cómo lograr la cura: "Fue la impunidad, el no respecto a la ley, y me parece que la única manera de sobrellevar es garantizar la vigencia de ley." Cristina Fernández sigue explicitando la historia reciente de su país: "¿Se imagina el trauma que impone en una sociedad el que sea el Estado el que viole las leyes? El terrorismo de Estado es algo más que la violación de las leyes, es el rompimiento del pacto fundante de la sociedad. Los que violaron la ley tienen que ser castigados por ello, porque, si no, retornamos a la época predemocrática, a la venganza por mano propia, a la ley del talión. La reconstrucción democrática hace imprescindible la finalización de la impunidad" (CRUZ, 2005).

Miren los pies de los bailarines de tango, cada cual va por su lado y no en tanto continúan en la misma dirección, avanzan, retroceden, se apartan, vuelven a estar juntos y siguen, siguen como la patria en pedazos que se rehace en su letras-líneas. Pero esta constatación no impide a Piglia contemplar con pesimismo el destino de su país. Señala que con frecuencia el impulso des-construccionista transige con las premisas reales, y termina su novela con la carta del suicida Enrique Ossorio no una carta de justificativas, una "cartatestamento" como a de nuestro y por muchos querido dictador el gaucho Getulio Vargas, no una carta mapa, una carta que indica un camino para aquellos que quieren trillar por el "desierto" argentino.

Carlos Gardel canta la vuelta, habla como un exilado, a pesar de no serlo. Piglia, un exilado que recusa el exilio cuenta su vuelta. El escritor crea un "crítica semiótica" de la ciudad a través de la cual, descifra el lenguaje de la dictadura, descodifica este lenguaje que es hecha de silencios y omisiones al exponer sus entrañas en los diceres más cotidianos de la administraciones públicas: "Zona de detención", un marco de la parada de autobús tornase una clave para saber los que pasa a los ciudadanos que no aceptan las "razones de Estado" vigentes. A vuelta poética de Gardel es imposible en la vuelta herida de Piglia, pero conviven, están en simultaneidad temporal en los discursos de la nacionalidad argentina. Por esto insisto en leerlas lado a lado.

\section{No exilarse}

Volver. Pero esa es otra historia En junio del ` 77 vuelvo, salgo a caminar por la ciudad. Con esa mirada única que tiene uno cuando vuelve. A un lugar después de mucho tiempo. Lo primero que me llama la atención es que los militares cambiaron el sistema de señales. En lugar de los viejos postes pintados de blanco que indicaban las paradas de colectivos han puesto unos carteles que dicen: Zona de detención. Tuve la impresión de que todo se había vuelto explícito, que esos carteles decían la verdad. La amenaza aparecía insinuada y dispersa por la ciudad. Como si se hiciera ver que Buenos Aires era una ciudad ocupada y que las tropas de ocupación habían empezado a organizar los traslados y asesinatos de la población sometida. La ciudad se alegorizaba. Por de pronto ahí estaba el terror nocturno que invadía todo y a la vez

\section{VOLVER}

Música de Carlos Gardel

Letra de Alfredo Le Pera

Compuesto en 1935

Yo adivino el parpadeo

de las luces que a lo lejos

van marcando mi retorno.

Son las mismas que alumbraron

con sus pálidos reflejos

hondas horas de dolor.

$Y$ aunque no quise el regreso,

siempre se vuelve al primer amor.

La vieja calle donde el eco dijo 
seguía la normalidad, la vida cotidiana, la gente que iba y venía por la calle. El efecto siniestro de esa doble realidad que era la clave de la dictadura. La amenaza explícita pero invisible que fue uno de los objetivos de la represión. Zona de detención: ese cartel se condensa la historia de la dictadura. tuya es su vida, tuyo es su querer,

bajo el burlón mirar de las estrellas

que con indiferencia hoy me ven volver...

Volver... con la frente marchita,

las nieves del tiempo platearon mi sien...

Sentir... que es un soplo la vida,

que veinte años no es nada,

que febril la mirada, errante en las sombras,

te busca y te nombra.

Vivir... con el alma aferrada

a un dulce recuerdo

que lloro otra vez...

Tengo miedo del encuentro

con el pasado que vuelve

a enfrentarse con mi vida.

Tengo miedo de las noches

que pobladas de recuerdos

encadenan mi soñar.

\section{Referências}

ABADIA, Sonia apud. MANRIQUE, Diego. El baile canalla. EP[S] El País Semanal. Número 1469. Domingo, 21 de noviembre de 2004.

BENJ AMIN, Walter. Ensayos escogidos. Buenos Aires: Sur, 1967

CORTÉS MORATÓ, Jordi y RIU, Antoni Martínez. Diccionario de filosofía en CD-ROM. Herder: Barcelona, 1996-99, s/n

CRUZ, Juan. Cristina Fernández de Kirchner: La mujer fuerte de Argentina. EP[S]: El País Semanal, Número 1477. Domingo, 16 de enero de 2005.

DE MORA, Carmen, Apuntes de aula. Sevilla, enero de 2005 BORGES, Jorge Luis. Prólogo. Informe de Brodie. Madrid, (1970) 2003

NIETZSCHE, Friedrich, Genealogia da Moral. trad: Paulo Cesar Souza. São Paulo: Brasiliense, 1988.

PIGILIA, Ricardo. Respiración Artificial. Buenos Aires: Sudamericana, (1988) 1993.

PIGLIA, Ricardo. "El tango y la tradición de la traición". En: Argentina en pedazos. Buenos Aires: Urraca, 1993.

PIGLIA, Ricardo. Formas Breves. Barcelona: Anagrama, 2000.

PIGLIA, Ricardo. "La lectura de la ficción”, “Conversación en Princeton” In: Crítica y Ficción, Barcelona: Anagrama, 1986.

Recebido em 08/9/06. Aprovado em 10/10/06.

Title: Fiction and Politics in Respiración Artificial: an inventory of limits

Author: Maria Cândida Ferreira de Almeida

Abstract: This paper presents a series of Ricardo Piglia's standpoints, marked by a concern with the "truth" in fiction; such standpoints, which appear in his narratives are focused on politics. Both, fiction and politics are analyzed and combined with my own viewpoints on literary criticism and politics. Among the series found in the work of the Argentinean writer I have selected the one that appeared to me to be the most important for also understanding the culture of his country: the opposition between fiction and reality, permeated by a certain notion of politics read under the metaphor of the tango. The paper closes with a confrontation between Piglia's words and those by Carlos Gardel.

Keywords: criticism; politics; Latin-American literature; Ricardo Piglia.

Titre: Fiction et Politique dans la Respiration Artificielle: un inventaire de limites

Auteur: Maria Cândida Ferreira de Almeida

Résumé: Ce travail présente une série de dispositions d'emplacements de Ricardo Piglia, marqués par le souci avec la "vérite" face à la fiction, produits dans l'œuvre narrative elle-même et centré en politique, tous les deux mélangés et analysés avec mes propres idées de critique littéraire et de politique J'ai choisi parmi les séries présentes dans l'œuvre de l'écrivain argentin celle qui m'a donné l'impression d'être la plus importante pour comprendre aussi la culture de son pays: l'opposition fiction et réalité, prise d'une certaine notion de politique travaille sous la métaphore du tango. Pour, à la fin, confronter les paroles de Piglia à celles de Carlos Gardel.

Mots-clés: critique ; politique; littérature latino-américaine; Ricardo Piglia.

Título: Ficção e política em "Respiración Artificial": um inventário de limites

Autor: Maria Cândida Ferreira de Almeida

Resumo: Este trabalho apresenta uma série de posicionamentos de Ricardo Piglia, marcados pela preocupação com a "verdade" frente ao ficcional, produzidos na própria obra narrativa e focados em política, ambas mescladas e analisadas com minhas próprias concepções de crítica literária e de política. Elegi entre as séries presentes na obra do escritor argentino a que me pareceu mais importante para compreender também a própria cultura de seu país: a oposição ficção e realidade, infiltrada por certa noção de política lida sob a metáfora do tango. Para, ao final, confrontar as palavras de Piglia com as de Carlos Gardel.

Palavras-chave: crítica; política; literatura latino-americana; Ricardo Piglia.

* Pós-doutorado (Fapesb-UFBA). mcandida74@yahoo.com.br

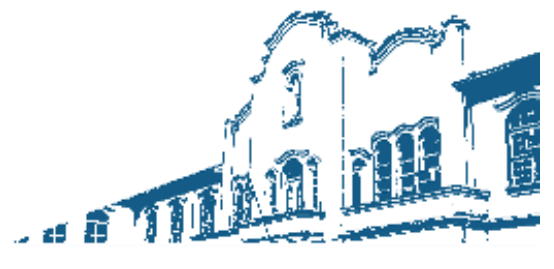

Copyright PPGCL/ Unisul 2006 @ (48) 3621-3369 - Desenvolvimento: Prof. Dr. Fábio J osé Rauen 